o

doi:10.5004/dwt.2017.20300

\title{
Calcium carbonate scales on process equipment: A measure of the induction time for nucleation
}

\author{
G. Mazziotti di Celso ${ }^{a}$, M. Prisciandaro ${ }^{b, *}$, D. Karatzac, A. Lancia ${ }^{\text {d }}$, D. Musmarra ${ }^{c}$ \\ ${ }^{a}$ University of Teramo, Faculty of Bioscience, Via C. Lerici, 1, 64023 Mosciano S.A. (TE), Italy, email: gmazziottidicelso@unite.it \\ 'University of L'Aquila, Department of DIIIE, viale Giovanni Gronchi 18, 67100 L'Aquila (AQ), Italy, \\ email:marina.prisciandaro@univaq.it \\ 'Second University of Naples, Department of DICDEA, via Roma 29, 81031 Aversa (CE), Italy, email: karatza@irc.cnr.it (D. Karatza) \\ dino.musmarra@unina2.it (D. Musmarra) \\ ${ }^{d}$ University of Federico II of Naples, Department of DICMAPI, p.le Tecchio 80, 80125 Naples (NA), Italy, email: lancia@unina.it
} Received 29 July 2016; Accepted 24 October 2016

\section{A B S T R A C T}

Scale deposition on process equipment surfaces has several disadvantages: in particular, when scales crystallize on heat transfer surfaces, they offer a resistance to the heat flow and can accumulate in pipelines, orifices and other flow passages seriously impeding the process flow. Moreover, calcium carbonate scales, together with calcium sulfate scales, are the major cause of fouling in reverse osmosis membranes, resulting in a continuous decline in desalted water production thus reducing the overall efficiency and increasing operation and maintenance costs. Therefore, from an economic point of view, the formation of these mineral scales is an obstacle to the recovery of potable water from sea or brackish waters as well as to the industrial utilization of many natural waters. The aim of the paper is to measure the induction time for calcium carbonate precipitation, through a well-assessed laser light scattering technique previously devised. Experiments are carried in a batch thermostated reactor at room temperature, $\mathrm{pH}$ in the range 7-8, in a supersaturation range from 2 to 200 . The induction time so measured could be used to estimate thermodynamic parameters such as the interfacial tension between crystals and mother suspension. The knowledge of interfacial tension is of major importance for guiding the choice of the most suitable additive for the inhibition of $\mathrm{CaCO}_{3}$ scale formation.

Keywords: Nucleation; Induction period; Calcium carbonate; Scale

\section{Introduction}

Calcium carbonate is, together with calcium sulphates, the main component of scales on process equipment surfaces. Their presence is mostly unwanted in several industrial applications, since scales reduce heat and mass transfer coefficients.

As for example, water desalination by membrane process is hindered by the presence of bicarbonates dissolved in raw water, which following warming of the feed decompose and carbonates precipitate on the membrane surface.

${ }^{*}$ Corresponding author.
Scaling causes a progressive wettability of the membrane, and as a result, the decline of both the permeate flux and the separation efficiency was observed [1-5].

Alkaline scales such as calcium carbonate can be controlled by maintaining $\mathrm{pH}$ below 7.5 with acidification. If sulfuric acid is added for $\mathrm{pH}$ control due to its low cost, the potential of calcium-sulfate scale formation is increased. Moreover, sulfuric acid can also cause system corrosion, which in turn can be an additional source of fouling. Thus, an ideal scale inhibitor would be able to prevent both calcium-carbonate precipitation at high $\mathrm{pH}$ and calcium-sulfate precipitation at low $\mathrm{pH}$ (neutral or slightly acidic) [6].

Presented at the EDS conference on Desalination for the Environment: Clean Water and Energy, Rome, Italy, 22-26 May 2016. 
The study of the effects of an additive on nucleation can be carried out by evaluating the induction period $\left(t_{i n d}\right)$, defined as the time elapsing between the onset of supersaturation and the formation of critical nuclei, or embryos [7-13].

The various experimental techniques detect with a different resolution the first portions of the crystalline phase, that nucleates and grows in a supersaturated solution. As a result, under otherwise equal conditions, induction time may not have the same value when measured by different techniques. However, this time primarily depends on solution supersaturation and temperature and it is the sum of two components: nucleation time $\left(t_{n}\right)$, related to the appearance of the critical nuclei, and growth time $\left(t_{q}\right)$, connected to the growth process, leading from critical nuclei to measurable crystals. Depending on the relative values of these two time periods, induction time can be influenced by nucleation alone $\left(t_{n} \gg t_{g^{\prime}}\right.$ nucleation-controlled induction period), by both mechanisms $\left(t_{n} \cong t_{g^{\prime}}\right.$ nucleation-andgrowth-controlled induction period) or by growth alone $\left(t_{n} \ll t_{g^{\prime}}\right.$ growth-controlled induction period) $[14,15]$. While $t_{g}$ can be estimated by a kinetic growth expression, $t_{n}$ is more difficult to quantify. Nevertheless, it is possible to discriminate whether the appearance of the new solid phase is controlled by nucleation and/or by growth, on the basis of the dependence of $t_{\text {ind }}$ on supersaturation.

In particular, if the process which takes place is truly homogeneous nucleation, i.e. it occurs in a clear solution under the effect of supersaturation alone, $t_{i n d}$ is inversely proportional to the nucleation rate, defined as the number of nuclei formed in solution per unit time and volume.

In this case, as shown by Mullin [16] and Söhnel and Garside [17], it is possible to use the experimental knowledge of the induction period to estimate the interfacial tension $\left(\gamma_{s}\right)$ between crystals and the surrounding solution for nucleation based on the dependence of $t_{\text {ind }}$ on supersaturation.
In this paper, preliminary results on calcium carbonate precipitation are reported; through a well-assessed laser light scattering technique previously devised, the induction time is measured at the temperature of $20^{\circ} \mathrm{C}, \mathrm{pH}$ in the range 7-8; the interfacial tension between crystals and mother solution is estimated.

\section{Materials and methods}

The experimental apparatus consists of a stirred reactor with a related optical device and is schematically shown in Fig. 1 . The reactor is a batch cylindrical crystallizer, made of glass, with a working volume of $1.1 \times 10^{-3} \mathrm{~m}^{3}$ and a diameter of $0.09 \mathrm{~m}$. The crystallizer is surrounded by a water jacket for temperature control; stirring is provided by a two-blade polypropylene stirrer, with rotation rate ranging between 1 and $10 \mathrm{~s}^{-1}$. An off-take tube, placed at half of the working height of the liquid, allows to withdraw samples of the suspension; the position of the tube has been chosen to ensure that the content of the exit stream is the same as the content of the reactor.

The stream removed by the off-take tube is sent, by a peristaltic pump, to an analysis flow-through cell, and then is conveyed again to the crystallizer. The cell, made of quartz, is $0.07 \mathrm{~m}$ long, with a square section of $2.5 \times 10^{-5} \mathrm{~m}^{2}$ and $0.0025 \mathrm{~m}$ thickness. A $10 \mathrm{~mW}$ He-Ne laser beam $\left(I_{0}=\right.$ $632.8 \mathrm{~nm}$ ) is focused on the cell, orthogonal to its walls; the beam, whose diameter is $2 \mathrm{~mm}$, is vertically polarized. On the path of the laser beam, placed at $45^{\circ}$ with respect to its direction, a beam splitter is provided in order to divide the laser beam into two parts; one is used to illuminate the measure cell, while the other, collected by a photodiode, allows to check the stability and the intensity of the laser beam $\left(I_{o}\right)$. The signal of the scattered light $\left(I_{\text {sca }}\right)$ is collected by two lenses of focal 120 and $50 \mathrm{~mm}$, at $90^{\circ}$ with respect to the

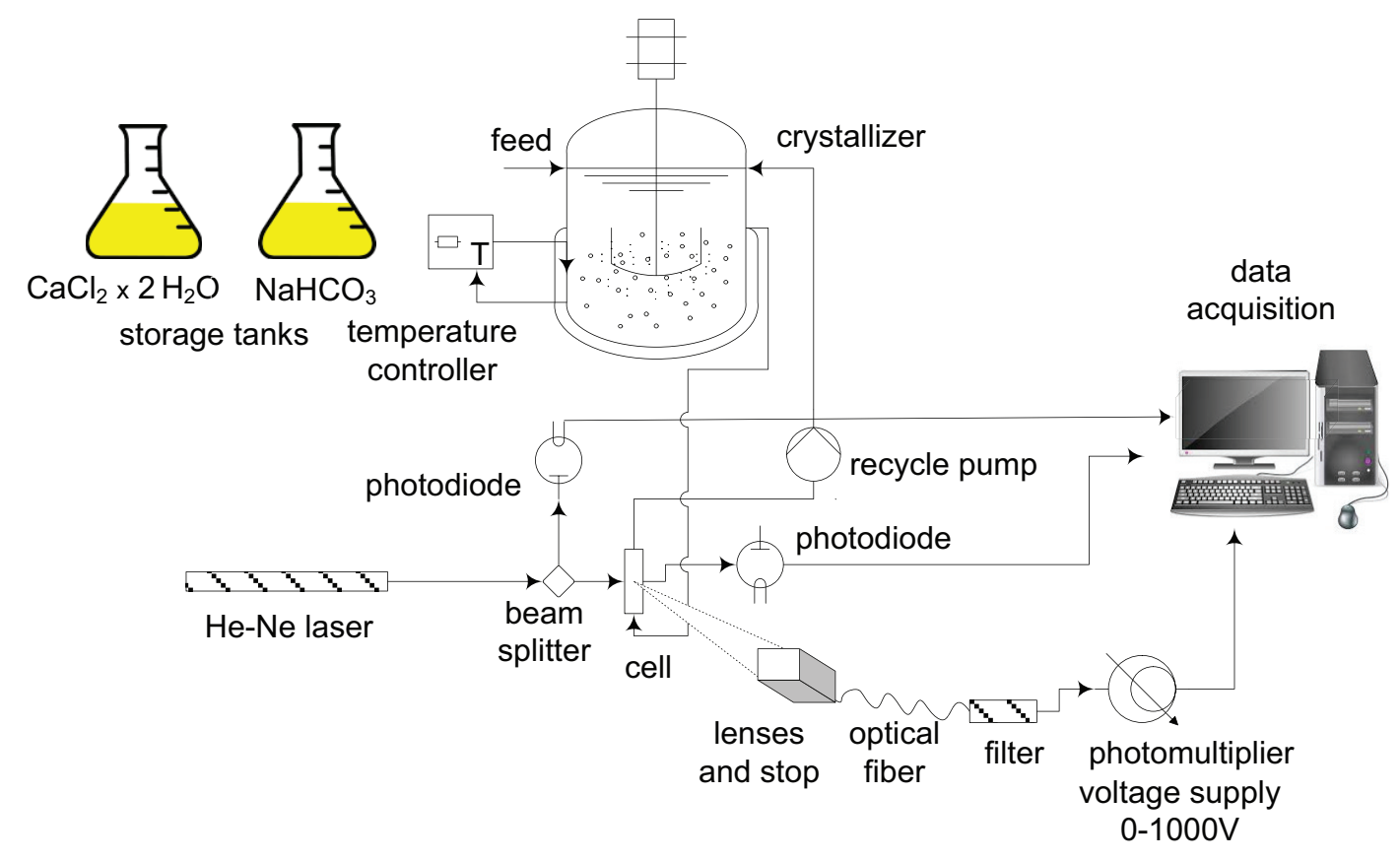

Fig. 1. Lab-scale experimental apparatus. 
laser beam; this signal is sent, through a quartz optical fiber which ends on an interferential filter, to a photomultiplier tube, connected to a power supply with voltage variable in the range of $0-1000 \mathrm{~V}$. The signal of the transmitted light $\left(I_{\text {trans }}\right)$ is collected by a photodiode located beyond the cell, at $0^{\circ}$ with respect to the laser beam. The two analogue signals of scattered and transmitted light, together with $I_{o^{\prime}}$ are collected by a recorder device.

Supersaturated solutions of calcium carbonate were prepared by mixing clear aqueous solutions of reagentgrade $\mathrm{CaCl}_{2} \cdot 2 \mathrm{H}_{2} \mathrm{O}$ and $\mathrm{NaHCO}_{3}$ (Applichem, Darmstadt, Germany). All Ca ${ }^{2+}$ ions concentration as $\mathrm{CaCO}_{3}$ was standardized through EDTA titrimetric method.

Once prepared all the solutions were filtered, by using a $0.45 \mathrm{~mm}$ filter (Millipore, HVLP 4700) and a vacuum pump (Vacuubrand, MZ4C), in order to eliminate all foreign materials inevitably present in the solution, and then mixed directly into the reactor. The equimolar concentration of $\mathrm{CaCl}_{2} \cdot 2 \mathrm{H}_{2} \mathrm{O}$ and $\mathrm{NaHCO}_{3}$ in the reactor varied between 2 and $36 \mathrm{~mol} / \mathrm{m}^{3}$. The supersaturation ratio was calculated considering the liquid-solid equilibrium between $\mathrm{Ca}^{2+}$ and $\mathrm{CO}_{3}^{2-}$ ions and solid $\mathrm{CaCO}_{3}$, as described by the following equation:

$\mathrm{Ca}^{2+}+\mathrm{CO}_{3}^{2-}=\mathrm{CaCO}_{3}$

so that it is:

$S=\frac{{ }^{a} a^{2+} a_{\mathrm{CO}_{3}^{2-}}}{K_{p s}}$

where $a_{J}$ represents the activity of the $J$ species $\left(J=\mathrm{Ca}^{2+}\right.$ $\mathrm{CO}_{3}^{2-}$ ) expressed as the product of the molality $\left(m_{\mathrm{T}}\right)$ and the activity coefficient $(\gamma)$, and $K_{p s}$ is the solubility product of calcium carbonate. The value of $K_{p s}$ was calculated as a function of temperature by means of the following relationship [18]:

$$
p K_{p s}=0.001183 T+8.03
$$

The concentration values of the $J$ species were calculated by solving a numerical model based on the equilibria that take place in the aqueous solution. The activity coefficients in the supersaturated solution were calculated by using a modified Deybe-Hückel equation. In equilibrium calculations, the transport of $\mathrm{CO}_{2}$ from and to the surrounding environment was neglected.

All the experiments were carried out at the temperature of $20^{\circ} \mathrm{C}$, while the supersaturation ratio changed in the range $2-200, \mathrm{pH}$ was in the range $7-8$. All experiments were performed in triplicate.

The induction period was evaluated by measuring the intensity of scattered and transmitted light signals as a function of time. These signals were processed to evaluate $t_{\text {ind }}$ by adopting two parallel procedures, one graphical and the other one numerical. These procedures, described in detail elsewhere [7], gave quite similar $( \pm 10 \%)$ results.

\section{Results and discussion}

As already said, preliminary experimental results include tests conducted by setting the temperature at the value $T=20^{\circ} \mathrm{C}$, with changing the supersaturation $S$ in the range $2-200$.

Fig. 2 reports the signal of transmitted light as a function of time for $S=67$. The figure shows the decrease of the signal with respect to its initial value, with individuating an induction time equal to about $130 \mathrm{~s}$.

Fig. 3 shows all the experimental results, showing the dependence of induction period on supersaturation, at $T=$ $25^{\circ} \mathrm{C}$.

The experimental data have been linearized according to the following semi-empirical correlation, on which the line reported in Fig. 2 is based on:

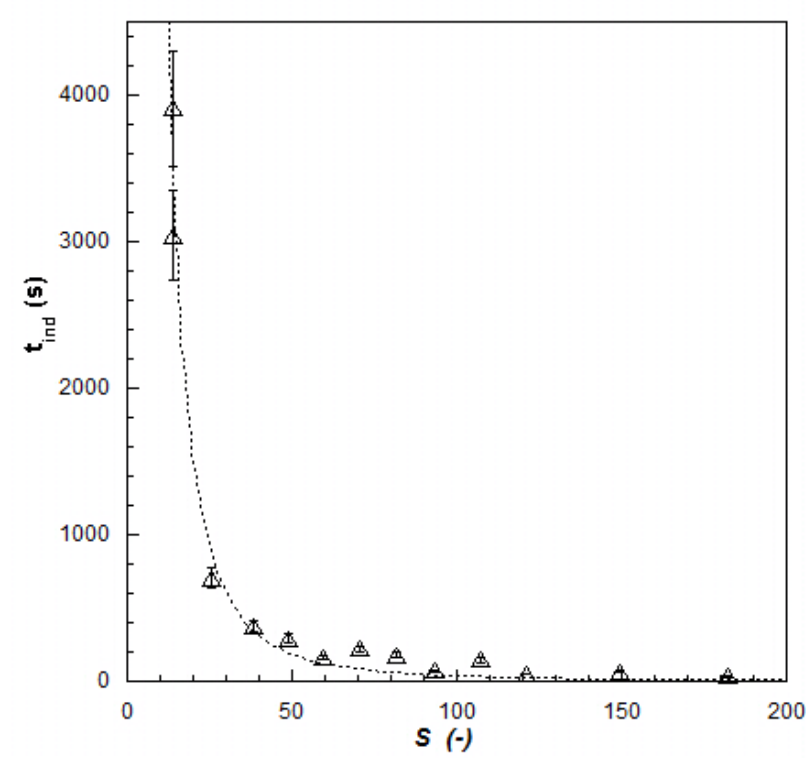

Fig. 2. Signal of transmitted light as a function of time; $S=67$, $T=25^{\circ} \mathrm{C}$.

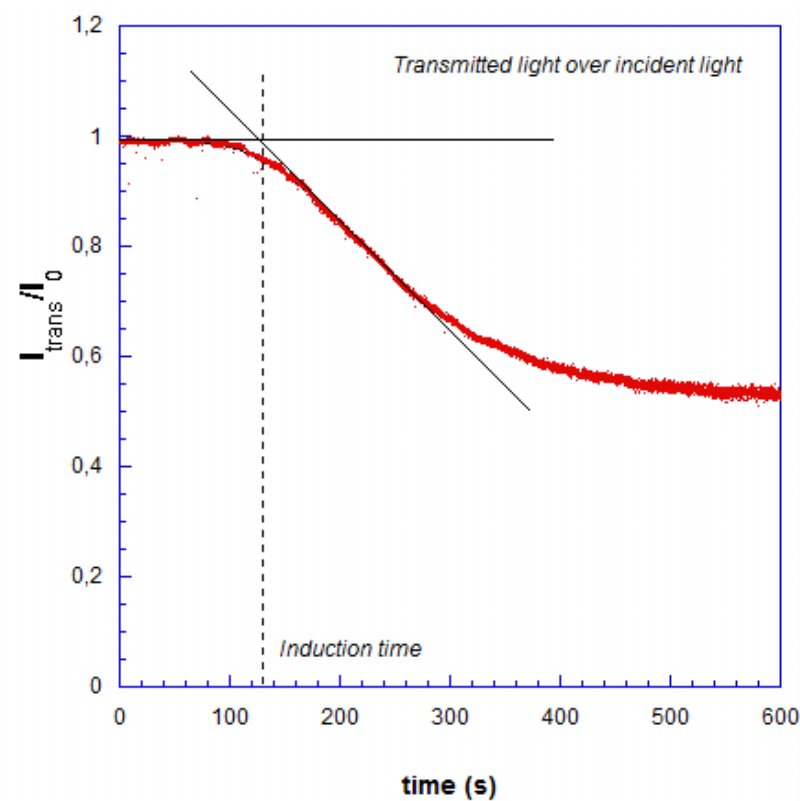

Fig. 3. Induction times as a function of supersaturation ratio $S$, $T=25^{\circ} \mathrm{C}$. 
$t_{\text {ind }}=\frac{K}{S^{r}}$

where $K$ and $r$ are empirical constants $\left(K=1.57 \times 10^{6}, r=\right.$ $2.32, \mathrm{R}^{2}=0.975$ ). This figure shows that the induction period for $\mathrm{CaCO}_{3}$ nucleation continuously decreases with increasing supersaturation.

Fig. 4 shows a comparison between calcium carbonate and calcium sulfate dehydrate in terms of the induction times as a function of $S$. From the figure it is well visible the very different behavior of the two scale forming salts: while induction times for gypsum nucleation spans from few minutes to almost an hour in a very narrow supersaturation range (2-2.7), to have the same $t_{\text {ind }}$ variations for calcium carbonate it is necessary to increase the supersaturation of two order of magnitude (2-200), at a fixed temperature. In other words, the distance of metastability curve from solubility curve for calcium carbonate appears higher then calcium sulfate dehydrate, that is the width of the metastable zone seems to be wider. This represents an advantage in scaling prevention, since a broad metastable zone would result in a more governable process. However, this circumstance should be confirmed by additional experiments carried out at different temperatures.

As already said, when carried out for a wide range of supersaturation, the experimental measurements of induction time at different supersaturation ratios can be used to estimate the interfacial tension between crystals and mother solution. By considering that the nucleation time is controlled by nucleation, as generally assumed for calcium carbonate crystallization [15], the linearization of the experimental points at $T=25^{\circ} \mathrm{C}$ (Fig. 5) has been conducted according to the following equation, derived from homo-

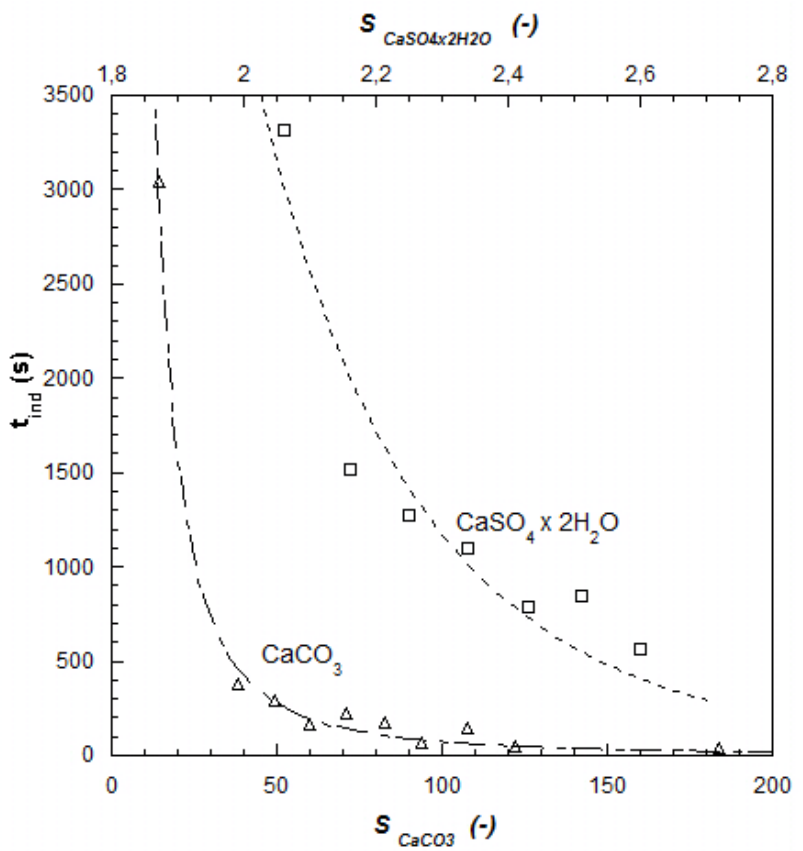

Fig. 4. Comparison among calcium sulfate and calcium carbonate induction times as a function of supersaturation ratio $S, T=$ $25^{\circ} \mathrm{C}$.

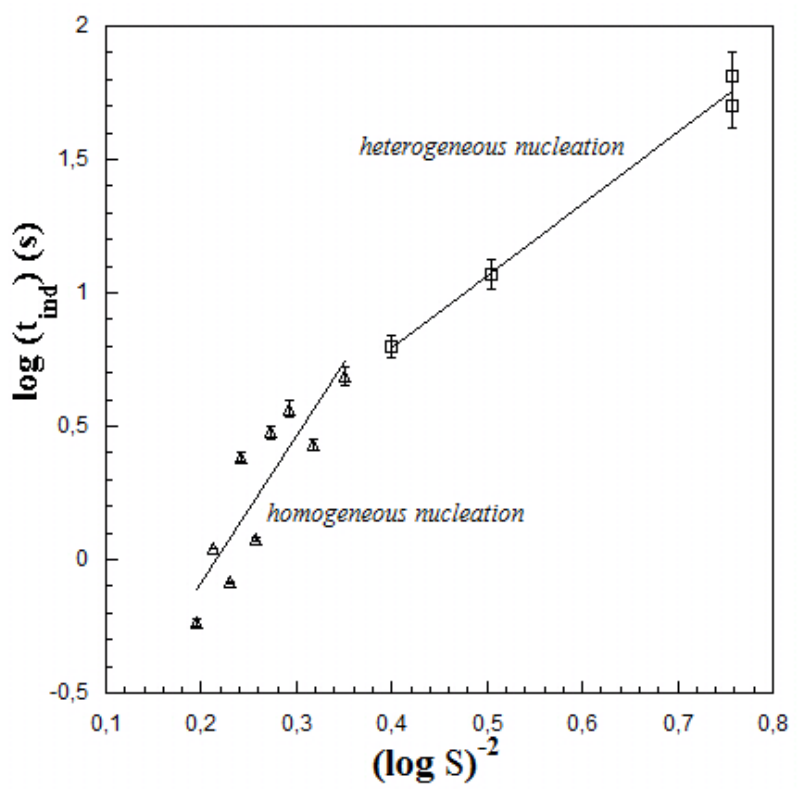

Fig. 5. Estimation of the interfacial tension, $T=25^{\circ} \mathrm{C}$.

geneous nucleation equations when nucleation is the controlling mechanism $\left(t_{n} » t_{g}\right)$ [17]:

$\log \left(t_{\text {ind }}\right)=C_{N}+\frac{D_{N}}{T^{3}(\log S)^{2}}$

where $C_{N}$ is an empirical constant and $D_{N}$ is given by:

$D_{N}=\frac{\beta \gamma_{s l}^{3} V_{m}^{2} N_{A} f(\phi)}{(2.3 R)^{3} v^{2}}$

where $\beta$ is a shape factor, $\gamma_{s l}$ is the surface energy, $N_{A}$ is the Avogadro number, $R$ is the gas constant, $V_{m}$ the molar volume, $v$ is the number of ions in which the molecule is dissociated and $f(\phi)$ is a correction factor which takes into account the heterogeneous nucleation; in particular, when purely homogeneous nucleation takes place it is $f(\phi)=1$ while when heterogeneous nucleation occurs it is $f(\phi)<1$. Consequently a change in the slope of the equation may indicate a transition from homogeneous to heterogeneous nucleation mechanisms.

The results of the linearization carried out on all $t_{\text {ind }}$ experimental homogeneous data (in Eq. (6) it was assumed $\beta=16 \pi / 3$, assuming spherical particle and $V_{m}=36.9 \mathrm{~cm}^{3} /$ mol; $R^{2}=0.87$ ) gave the value of $\gamma_{s l}=109.3 \mathrm{~mJ} / \mathrm{m}^{2}$, that is in a good agreement with other available literature values [14-16], thus confirming a posteriori the considered nucleation mechanism.

\section{Conclusions}

In this paper, preliminary results on calcium carbonate crystallization are reported. In details, the induction time for carbonate crystallization has been measured at the constant temperature of $25^{\circ} \mathrm{C}$, at a supersaturation ratio ranging from 2 to $200, \mathrm{pH}$ in the range 7-8, by using a laser well 
assessed optical technique. The measured induction times show a strong dependence on supersaturation, from which it will be possible to estimate the interfacial tension between crystals and mother solution. A comparison of two main scale forming salts, calcium carbonate and calcium sulfate dehydrate, has shown that the first seems to have a wider metastable zone. Moreover, from the linearization of the obtained results, the interfacial tension between calcium carbonate crystals and mother solution has been estimated to be $\gamma_{s l}=109.3 \mathrm{~mJ} / \mathrm{m}^{2}$.

\section{References}

[1] M. Gryta, Polyphosphates used for membrane scaling inhibition during water desalination by membrane distillation Desalination, 285 (2012) 170-176.

[2] M. Gryta, Alkaline scaling in the membrane distillation process, Desalination, 228 (2008) 128-134.

[3] F. He, K.K. Sirkar, J. Gilron, Effects of antiscalants to mitigate membrane scaling by direct contact membrane distillation, J. Membr. Sci., 345 (2009) 53-58.

[4] M. Prisciandaro, G. Mazziotti di Celso, Back-flush effects on superficial water ultrafiltration, Desalination, 256 (2010) 22-26.

[5] A. Salladini, M. Prisciandaro, D. Barba, Ultrafiltration of biologically treated wastewater by using backflushing, Desalination, 207 (2007) 24-34.

[6] F. Change, Z. Yuming, L. Guangqing, H. Jingyi, S. Wei, W. Wendao, Inhibition of $\mathrm{Ca}_{3}\left(\mathrm{PO}_{4}\right)^{2}, \mathrm{CaCO}_{3^{\prime}}$ and $\mathrm{CaSO}_{4}$ Precipitation for industrial recycling water. Ind. Eng. Chem. Res., 50 (2011) 10393-10399.
[7] M. Prisciandaro, A. Lancia, D. Musmarra, Gypsum nucleation into sodium chloride solutions, AIChE J., 47 (2001a) 929-934.

[8] M. Prisciandaro, A. Lancia, D. Musmarra, Calcium sulfate dihydrate nucleation in the presence of calcium and sodium chloride salts, Ind. Eng. Chem. Res., 40 (2001b) 2335-2339.

[9] M. Prisciandaro, A. Lancia, D. Musmarra, The retarding effect of citric acid on calcium sulfate nucleation kinetics. Ind. Eng. Chem. Res., 42 (2003) 6647-6652.

[10] M. Prisciandaro, E. Olivieri, A. Lancia, D. Musmarra, Gypsum precipitation from an aqueous solution in the presence of nitrilotrimethylenephosphonic acid. Ind. Eng. Chem. Res., 45 (2006) 2070-2076.

[11] M. Prisciandaro, E. Olivieri, A. Lancia, D. Musmarra, Gypsum scale control by Nitrilotrimethylenephosphonic acid. Ind. Eng. Chem. Res., 48 (2009) 10877-10883.

[12] M. Prisciandaro, E. Olivieri, A. Lancia, D. Musmarra, PBTC as an antiscalant for gypsum precipitation: Interfacial tension and activation energy estimation, Ind. Eng. Chem. Res., 51 (2012) 12844-12851.

[13] M. Prisciandaro, A. Lancia, D. Musmarra, G. Mazziotti di Celso, Gypsum scale inhibition on process equipment surfaces: a review, Chem. Eng. Trans., 39 (2014) 775-780.

[14] O. Söhnel, J.W. Mullin, A method for the determination of precipitation induction periods. J. Crystal Growth, 44 (1978) 377382.

[15] O. Söhnel, J.W. Mullin, Interpretation of crystallization induction periods. J. Colloid Interface Sci., 123 (1988) 43-50.

[16] J.W. Mullin, Crystallization, 4th edition, Butterworth-Heinemann Ltd, Oxford, 2001.

[17] O. Söhnel, J. Garside, Precipitation : basic principles and industrial applications, Butterworth-Heinemann, Oxford, 1992.

[18] T.E. Larson, A.M. Buswall, Calcium carbonate saturation index and alkalinity interpretations. J. AWWA, 34 (1942) 1667-1678. 